\title{
Medium Optimization for the Production of Lipidless Biomass By Cunninghamella sp. 2A1 Using Response Surface Methodology
}

\author{
Siti Aminah, S., Aidil, A. H.* and Wan Mohtar, W. Y. \\ School of Biosciences and Biotechnology, Faculty of Science and Technology, \\ Universiti Kebangsaan Malaysia, 43600 Bangi, Selangor, Malaysia \\ E-mail: aidilah@pkrisc.cc.ukm.my
}

\begin{abstract}
A statistical design approach has been used to optimize the production of biomass by Cunninghamella sp. $2 \mathrm{~A} 1$, evaluated based on lipidless biomass. A $2^{3}$ full factorial central composite design (CCD) was chosen to study the combined effects of three factors; ammonium tartrate, peptone and glucose concentrations. The $p$-value for each factor was $<0.05$ suggesting that these factors have significant effects on the production of lipidless biomass. The production is represented by a linear model with $\mathrm{p}$-value $<0.0001$. The optimized medium consisting of $3.86 \mathrm{~g} / \mathrm{L}$ ammonium tartrate, $55.84 \mathrm{~g} / \mathrm{L}$ glucose and $7.73 \mathrm{~g} / \mathrm{L}$ peptone predicted a lipidless biomass of $16.83 \mathrm{~g} / \mathrm{L}$. Results from four replications based on the optimized medium produced an average of $18.48 \mathrm{~g} / \mathrm{L}$ lipidless biomass, which is in close agreement with the predicted value. The coefficient for glucose was the highest indicating it to be the most significant factor affecting lipidless biomass production.
\end{abstract}

Keywords: Medium optimization, Cunninghamella sp. 2A1, Lipidless biomass, Response surface.

\section{INTRODUCTION}

Polyunsaturated fatty acids (PUFA) play an important role as precursors for a variety of metabolites (such as prostaglandins and leukotrienes) that regulate critical biological functions. The first commercial-scale microbial lipid production was developed in 1985 in the United Kingdom using Mucor circinelloides, an oleaginous fungus producing lipid containing $15-18 \% \mathrm{Y}$-linolenic acid (GLA) (of total fatty acid) (Ratledge 1992). Production of lipid is very much dependent on medium composition and for a new isolate, this aspect needs intensive investigation especially in relation to biomass concentration and lipid content. Our preliminary data involving the investigation of four medium components (ammonium tartrate, peptone, yeast extract and glucose) indicated that ammonium tartrate, peptone and glucose affect the biomass production of Cunninghamella sp. 2A1 which is an important aspect in the optimization of lipid production (Siti Aminah et al., 2004). Data on lipidless biomass, usually not reported in literature, gave new insight into effect of medium composition on lipid production. Therefore, these three factors were chosen for further optimization for lipidless biomass production using response surface methodology (RSM).

Optimizations of media are normally carried out by varying one parameter at a time whilst keeping the others constant. RSM is a technique for studying the effect of several factors acting together and affecting the responses by varying them in a number of experiments (Maddon and Richard 1977). RSM had been successfully applied in the optimization of medium composition for the production of glucosyltransferase by Aspergillus niger

${ }^{*}$ Corresponding author
(Lee and Chen 1997), optimization of growth medium for the production of CGTase from Bacillus sp. (Rahman et al., 2004; Ibrahim et al., 2005) and optimization of culture medium for production of lovastatin by Monascus ruber (Chang et al., 2002).

This study reports the application of RSM to optimize lipidless biomass production using oleaginous GLAproducing local fungal isolate, Cunninghamella sp. 2A1. The assessment of the actual biomass concentration was carried out based on lipidless biomass as lipid content contributed up to $30 \%(\mathrm{w} / \mathrm{w})$ of biomass. The relationship between the selected factors (concentrations of ammonium tartrate, glucose and peptone), and their interactions and influences on the measured responses were established.

\section{MATERIALS AND METHODS}

\section{Microorganism and culture condition}

Cunninghamella sp. 2A1 was obtained from the School of Biosciences and Biotechnology, Faculty of Science and Technology, Universiti Kebangsaan Malaysia, Bangi, Selangor, Malaysia. The cultures were maintained at $4^{\circ} \mathrm{C}$ and were subcultured at regular intervals. Inoculum was prepared by transferring $1 \mathrm{ml}$ of spore suspension into $100 \mathrm{ml}$ of nitrogen-limited medium (Kendrick and Ratledge 1992) and incubating at $30^{\circ} \mathrm{C}, 250 \mathrm{rpm}$ for $48 \mathrm{~h}$. The composition $(\mathrm{g} / \mathrm{L})$ of medium comprises: ammonium tartrate, $1.0 ; \mathrm{KH}_{2} \mathrm{PO}_{4}, 7.0 ; \mathrm{Na}_{2} \mathrm{HPO}_{4}, 2.0 ; \mathrm{MgSO}_{4} .7 \mathrm{H}_{2} \mathrm{O}$, 1.5; yeast extract, $1.5 ; \mathrm{CaCl}_{2}, 0.1 ; \mathrm{FeCl}_{3} .6 \mathrm{H}_{2} \mathrm{O}, 0.008$; $\mathrm{ZnSO}_{4} .7 \mathrm{H}_{2} \mathrm{O}, \quad 0.0001 ; \quad \mathrm{CuSO}_{4} .5 \mathrm{H}_{2} \mathrm{O}, \quad 0.0001$; $\mathrm{Co}\left(\mathrm{NO}_{3}\right)_{2} .6 \mathrm{H}_{2} \mathrm{O}, 0.0001 ; \mathrm{MnSO}_{4} .5 \mathrm{H}_{2} \mathrm{O}, 0.0001$. Glucose, 
$30 \mathrm{~g} / \mathrm{L}$ was sterilized $\left(121^{\circ} \mathrm{C}\right.$ for $\left.15 \mathrm{~min}\right)$ and added separately.

$10 \%(\mathrm{v} / \mathrm{v})$ of the seed culture was used as inoculum for batch fermentation in a $500 \mathrm{ml}$ flask containing $100 \mathrm{ml}$ of medium. Medium composition was varied based on the experimental design using Design Expert Version 6.0.10 (Section 2.3.). Cultivation was then carried out at $250 \mathrm{rpm}$ and $30^{\circ} \mathrm{C}$ for $120 \mathrm{~h}$. Cultures were harvested after $120 \mathrm{~h}$ of fermentation and the biomass concentration and lipid content were determined.

\section{Analytical methods}

\section{Determination of cell dry weight}

Biomass was harvested by filtering $100 \mathrm{ml}$ of the culture through a filter paper (Whatman No.1), washing extensively with distilled water and freeze-drying for $24 \mathrm{~h}$. The dry weight of cell was determined using a balance (AND GR-200). Lipidless biomass was calculated by subtracting the amount of lipid per liter culture from the biomass produced per liter culture.

\section{Determination of ammonium and glucose concentration}

Ammonium concentration was measured using indophenol method (Chaney and Marbach 1962). The glucose concentration was determined using a glucose oxidase Perid-test kit (Boehringer Mannheim). The optical density (OD) for ammonium and glucose determination was carried out at $625 \mathrm{~nm}$ and $500 \mathrm{~nm}$ (JASCO UV-VIS Spectrophotometer), respectively.

\section{Extraction of lipid}

Lipid was extracted using chloroform and methanol in a ratio of 2:1 (v/v) (Folch et al., 1957) overnight before filtering. The filtrate was washed with $150 \mathrm{ml}$ of $\mathrm{NaCl}(1 \%)$ followed by $150 \mathrm{ml}$ of distilled water. The chloroform layer was obtained and evaporated using rotary evaporator (BUCHI Rotavapor R-124). Lipid residue was dissolved in a minimal amount of diethyl ether and transferred to a tared vial.

\section{Experimental design}

Experimental design was determined using Design Expert Software Version 6.0.10 (State-Ease Inc., Minneapolis, USA). A $2^{3}$ full factorial CCD was used for three independent factors with six replication of the central points and six axial points, leading to a total of 20 sets of experiments. Low and high factor settings were coded as -1 and +1 respectively, the centre point was coded as 0 and the design was extended up to $+\alpha$ and $-\alpha(\alpha=1.682)$ (Table 1). The value of alpha represents the distance from the centre of the design space to an axial point. The optimal concentrations of factors were obtained by a numerical optimization procedure and analysing the response surface plots (Myers and Montgomery 1995).
Table 1: Factor settings in the form of coded values

\begin{tabular}{lrrrrc}
\hline \multicolumn{1}{c}{ Factors } & \multicolumn{5}{c}{ Level of factors } \\
& \multicolumn{1}{c}{$\boldsymbol{\alpha}$} & \multicolumn{1}{c}{} & \multicolumn{1}{c}{$\mathbf{0}$} & $\boldsymbol{+ 1}$ & $\boldsymbol{+} \boldsymbol{\alpha}$ \\
\hline Ammonium tartrate & 1.32 & 2 & 3 & 4 & 4.68 \\
$\left(\mathrm{X}_{1}, \mathrm{~g} / \mathrm{L}\right)$ & & & & \\
Glucose $\left(\mathrm{X}_{2}, \mathrm{~g} / \mathrm{L}\right)$ & 23.18 & 30 & 40 & 50 & 56.82 \\
Peptone $\left(\mathrm{X}_{3}, \mathrm{~g} / \mathrm{L}\right)$ & 2.64 & 4 & 6 & 8 & 9.32 \\
\hline
\end{tabular}

From the experimental results, an approximate polynomial relationship for dependent factors of lipidless biomass production was obtained. The result of this design was used to fit a first-order model,

$$
\begin{array}{ll}
k & \beta_{0}+\sum_{i=1} \beta_{i} x_{i} \ldots . .(1) \quad \begin{array}{l}
Y \text { is the predicted response; } \\
\beta_{0}, \beta_{l}, \text { are the constant } \\
\text { coefficients, and } X_{i} \text { is the } \\
\text { coded independent factor. }
\end{array}
\end{array}
$$

\section{RESULTS AND DISCUSSION}

Table 2 shows the predicted, actual and residual values of twenty runs. The results showed that the predicted values closely matched the actual values.

\section{Model selection}

Table 3 shows the sequential model sum of squares for the lipidless biomass and how terms of increasing complexity contribute to the total model. From that, the linear coefficient showed a significant result of $p$-value was $<0.0001$. P-values for two-factor interaction $(2 \mathrm{FI})$, quadratic and cubic models for lipidless biomass production were $>0.05$, meaning that the interactions among factors were not significant. This indicates that the linear model was accurate in describing or predicting the effect of significant factors on the production of lipidless biomass from Cunninghamella sp. 2A1.

\section{Model fitting}

ANOVA was used to evaluate the adequacy of the fitted model (Table 4). The fisher F-test with a very low probability value $(<0.0001)$ for response (lipidless biomass) demonstrated a high significance for the regression model. The goodness of fit of the model was checked by the determination coefficient $\left(R^{2}\right)$ (Haalland 1989). The R-squared value provided a measure of the variability in the actual response values that could be explained by the experimental factors and their interactions. A value of one represents the ideal case at which $100 \%$ of the variation in the observed value can be explained by the model (Khuri and Cornell 1987). In this case, the value of $R^{2}$ for lipidless biomass was 0.9511 indicating that only $4.89 \%$ of the total variations were not explained by the model. 
Mal. J. Microbiol. Vol 2(1) 2006, pp.40-45

Table 2: Experimental design of 20 runs of $2^{3}$ full factorial CCD with predicted, actual and residual values of each run

\begin{tabular}{|c|c|c|c|c|c|c|}
\hline \multirow[b]{2}{*}{ Run } & \multicolumn{3}{|c|}{ Factors } & \multicolumn{3}{|c|}{ Response } \\
\hline & $X_{1}(g / L)$ & $X_{2}(g / L)$ & $X_{3}(g / L)$ & Actual & $\begin{array}{c}\text { Lipidless biomass ( } g / L) \\
\text { Predicted }\end{array}$ & Residual \\
\hline 1 & -1 & -1 & -1 & 9.89 & 9.11 & 0.78 \\
\hline 2 & +1 & -1 & -1 & 9.68 & 10.12 & -0.44 \\
\hline 3 & -1 & +1 & -1 & 12.85 & 13.37 & -0.52 \\
\hline 4 & +1 & +1 & -1 & 14.72 & 14.37 & 0.35 \\
\hline 5 & -1 & -1 & +1 & 10.91 & 10.50 & 0.41 \\
\hline 6 & +1 & -1 & +1 & 11.10 & 11.50 & -0.40 \\
\hline 7 & -1 & +1 & +1 & 14.69 & 14.76 & -0.07 \\
\hline 8 & +1 & +1 & +1 & 15.37 & 15.76 & -0.39 \\
\hline 9 & $-\alpha$ & 0 & 0 & 11.51 & 11.59 & -0.08 \\
\hline 10 & $+\alpha$ & 0 & 0 & 14.07 & 13.28 & 0.79 \\
\hline 11 & 0 & $-\alpha$ & 0 & 8.67 & 8.86 & -0.19 \\
\hline 12 & 0 & $+\alpha$ & 0 & 16.40 & 16.01 & 0.39 \\
\hline 13 & 0 & 0 & $-\alpha$ & 11.28 & 11.27 & 0.01 \\
\hline 14 & 0 & 0 & $+\alpha$ & 13.98 & 13.60 & 0.38 \\
\hline 15 & 0 & 0 & 0 & 12.11 & 12.44 & -0.33 \\
\hline 16 & 0 & 0 & 0 & 10.25 & 12.44 & -2.19 \\
\hline 17 & 0 & 0 & 0 & 13.34 & 12.44 & 0.90 \\
\hline 18 & 0 & 0 & 0 & 12.43 & 12.44 & -0.01 \\
\hline 19 & 0 & 0 & 0 & 13.06 & 12.44 & 0.62 \\
\hline 20 & 0 & 0 & 0 & 12.40 & 12.44 & -0.04 \\
\hline
\end{tabular}

Table 3: Sequential model sum of squares for lipidless biomass $(\mathrm{g} / \mathrm{L})$

\begin{tabular}{lcccccc}
\hline \multicolumn{1}{c}{ Source } & $\begin{array}{c}\text { Sum of } \\
\text { squares }\end{array}$ & $\begin{array}{c}\text { Degrees of } \\
\text { freedom }\end{array}$ & Mean square & F-value & P-value \\
\hline Mean & 2992.80 & 1 & 2992.80 & & & Suggested \\
Linear & 71.78 & 3 & 23.93 & 97.18 & $<0.0001$ & Aliased \\
$2 \mathrm{FI}$ & 0.90 & 3 & 0.30 & 1.30 & 0.3207 & \\
Quadratic & 0.18 & 3 & 0.059 & 0.20 & 0.8920 & \\
Cubic & 1.37 & 4 & 0.34 & 1.38 & & \\
Residual & 1.24 & 5 & 0.25 & & & \\
Total & 3068.28 & 19 & 161.49 & & & \\
\hline
\end{tabular}

* $2 \mathrm{FI}$ - 2-factor interaction

Table 4: ANOVA for response surface linear model for lipidless biomass $(\mathrm{g} / \mathrm{L})$ after $120 \mathrm{~h}$ fermentation

\begin{tabular}{lccrrr}
\hline Source & $\begin{array}{c}\text { Sum of } \\
\text { squares }\end{array}$ & $\begin{array}{c}\text { Degrees of } \\
\text { freedom }\end{array}$ & Mean square & F-value & P-value \\
\hline Model & 71.78 & 3 & 23.93 & 97.18 & $<0.0001$ \\
Ammonium tartrate & 3.42 & 1 & 3.42 & 13.89 & 0.0020 \\
Glucose & 61.79 & 1 & 61.79 & 250.97 & $<0.0001$ \\
Peptone & 6.57 & 1 & 6.57 & 26.67 & 0.0001 \\
Residual & 3.69 & 15 & 0.25 & 0.92 & 0.5897 \\
Lack of Fit & 2.65 & 11 & 0.24 & & \\
Pure Error & 1.05 & 4 & 0.26 & & \\
Correlation Total & 75.48 & 18 & & &
\end{tabular}

$\mathrm{R}^{2}=0.9511, \mathrm{R}=0.9752$, Adjusted $\mathrm{R}^{2}=0.9413 \quad{ }^{*}$ significance $(\%)=\mathrm{p}<0.05$ 
The value of the adjusted $R^{2}$ is also high, which indicates a high significance of the model. A higher value of the correlation coefficient $(R=0.9752)$ signifies an excellent correlation between the independent factors. An insignificant lack of fit indicated that the model fits the data. The lack of fit tests compares the residual error to the pure error from replicated design points. The lack of fit F-value of 0.92 for lipidless biomass implies it is not significant relative to the pure error.

The key to lipid accumulation lies in allowing the amount of nitrogen supplied to the culture to become exhausted which means that cell proliferation stopped. The excess available carbon continues to be assimilated by the cells and are converted directly into lipid (Ratledge 1997). Our results (Siti Aminah et al., 2004) indicated that high lipidless biomass concentration does not necessarily correspond to high lipid content is also high. Although, lipid synthesis are not growth-associated, the lipid accumulation and yields however, could be significantly affected by the growth media in different species (Dyal et al., 2005). Our results are in agreement with these reports and that there exist a ranged direct correlation between lipidless biomass and lipid content. An increase in lipidless biomass beyond the critical value does not result in a corresponding increase in lipid content.

Based on Table 4, the concentration of ammonium tartrate, glucose and peptone are significant factors $(p<0.05)$ affecting lipidless biomass. Generally, nitrogen and carbon sources which are supplied from these medium components are required for biomass production (Stanbury et al., 1984). The carbon source (glucose) was used as an energy supply for both biosynthesis and viable cell maintenance as well as for cell biosynthesis (Adour et al., 2006). Nitrogen is known to be an essential component of nearly all complex macromolecules in fungal cells, such as protein, nucleic acids and cell wall components (Burkovski 2003). Our previous study showed that increasing the concentration of ammonium tartrate in medium led to an increase in biomass concentration (Siti Aminah et al., 2004). Supplementation with a nitrogen source in a peptide form (peptone) was more positive for yeast metabolism, inducing higher biomass and metabolite production (da Cruz et al., 2002). Other Mortierella sp. and Mucor sp. showed similar observation as determined in this study where glucose concentration of $30 \mathrm{~g} / \mathrm{L}$ up to $50 \mathrm{~g} / \mathrm{L}$ yielded good growth and lipid production (Wynn et al., 2001).

From the regression equation, it is predicted that increasing the concentrations of ammonium tartrate $\left(X_{1}\right)$, glucose $\left(X_{2}\right)$ and peptone $\left(X_{3}\right)$ should enhance lipidless biomass production. The regression equation of the model for lipidless biomass in terms of coded values showed significant positive linear effects for all three factors. The factor with the largest effect was glucose concentration $\left(X_{2}\right)$ followed by peptone concentration $\left(X_{3}\right)$ and ammonium tartrate concentration $\left(\mathrm{X}_{1}\right)$.

The regression equation:

Lipidless biomass $(\mathrm{g} / \mathrm{L})=12.55+0.50 \mathrm{X}_{1}+2.13 \mathrm{X}_{2}+0.69 \mathrm{X}_{3}$
The one factor plot for the lipidless biomass shows the linear effect of changing the level of a single factor with the other two being at their zero level (Figure 1-3). As can be seen, an increase in ammonium tartrate, glucose and peptone led to an increase in lipidless biomass production.

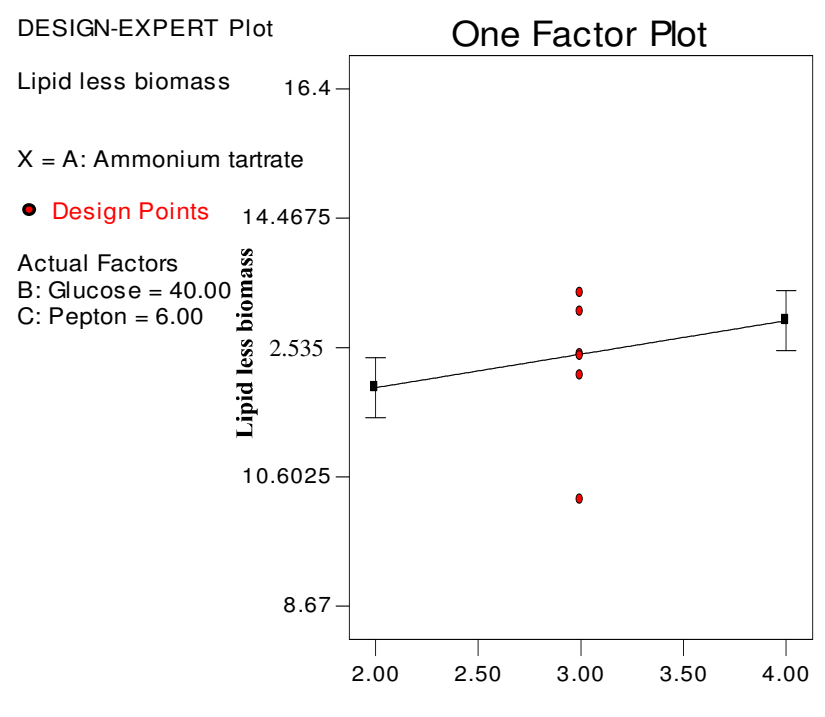

A: Ammonium tartrate

Figure 1: Effect of ammonium tartrate concentration on the lipidless biomass by Cunninghamella sp.2A1

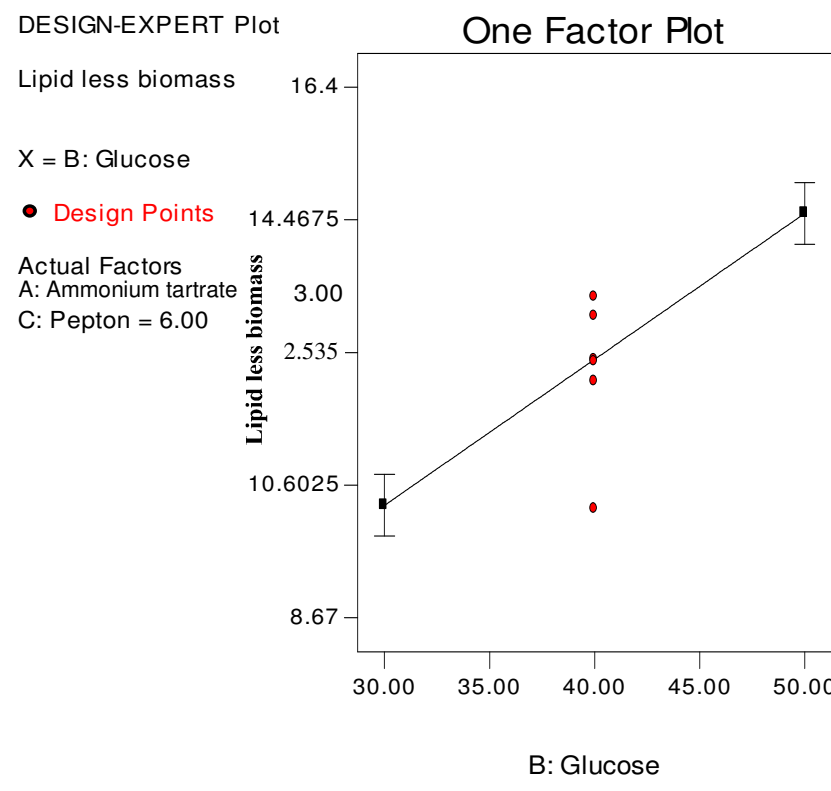

Figure 2: Effect of glucose concentration on the lipidless biomass by Cunninghamella sp.2A 1 


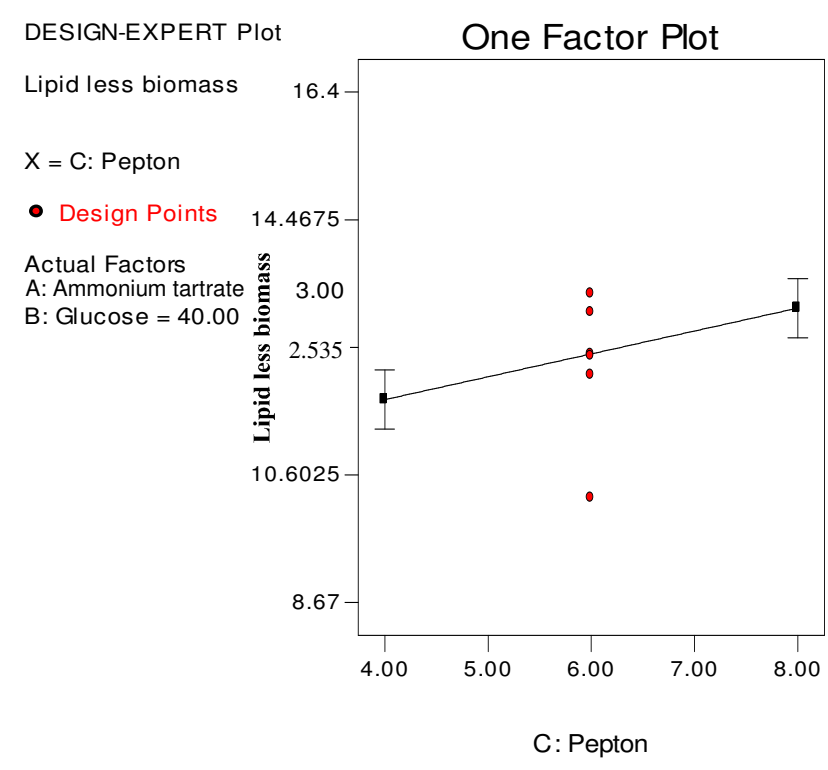

Figure 3: Effect of peptone concentration on the lipidless biomass by Cunninghamella sp.2A1

\section{Numerical optimization of factors}

Based on Table 2 (run no.12), the highest concentration of lipidless biomass $(16.4 \mathrm{~g} / \mathrm{L})$ and gave lipidless biomass yield $(0.35 \mathrm{~g} / \mathrm{g}$ glucose utilized) from Cunninghamella $\mathrm{sp}$. $2 \mathrm{~A} 1$ was obtained when the concentration of ammonium tartrate, glucose and peptone were $3.0,56.82$ and $6.0 \mathrm{~g} / \mathrm{L}$, respectively. To obtain the maximum optimum activity, the factor levels and response were set at the desired goal using Design Expert's Numerical Optimization with desirability level equal to one. Optimal concentrations of ammonium tartrate, glucose and peptone were established as $3.86 \mathrm{~g} / \mathrm{L}, \quad 55.84 \mathrm{~g} / \mathrm{L}$ and $7.73 \mathrm{~g} / \mathrm{L}$, respectively. This solution gives the predicted response for lipidless biomass as $16.83 \mathrm{~g} / \mathrm{l}$. From four replications of the experiment under suggested optimal concentrations, an average lipidless biomass of $18.48 \mathrm{~g} / \mathrm{L}$ and lipidless biomass yield of $0.41 \mathrm{~g} / \mathrm{g}$ glucose utilized was achieved. This indicates an increase of $17 \%$ in efficiency of glucose utilization under optimized medium condition. The result correlates well with the predicted value and the model was proven to be adequate.

\section{CONCLUSION}

CCD and response surface methodology were useful to determine the optimum concentration levels of medium components that significantly influence the yield of lipidless biomass from Cunninghamella sp. 2A1. The final composition of the defined medium to produce $18.48 \mathrm{~g} / \mathrm{L}$ of lipidless biomass and lipidless biomass yield of $0.41 \mathrm{~g} / \mathrm{g}$ glucose utilized after the optimization procedure was as follows: $3.86 \mathrm{~g} / \mathrm{L}$ ammonium tartrate; glucose $55.84 \mathrm{~g} / \mathrm{L}$ and peptone $7.73 \mathrm{~g} / \mathrm{L}$.

\section{ACKNOWLEDGEMENTS}

The authors would like to thank the Ministry of Science, Technology and Innovation, Malaysia for financial support under IRPA 09-02-02-001 (BTK/TD/001).

\section{REFERENCES}

Adour, L., Couriol, C. and Amrane, L. (2006). Organic or mineral nitrogen source during Penicillium camembertii growth on glucose limited medium. Enzyme and Microbial Technology. 38: 55-59.

Burkovski, A. (2003). Ammonium assimilation and nitrogen control in Corynebacterium glutamicum and its relatives: an example for new regulatory mechanisms in actinomycetes. FEMS Microbiology Reviews. 27: 617-628.

Chaney, A.L. and Marbach, E.P. (1962). Modified reagents for determination of urea and ammonium. Clinical Chemistry. 8: 130-132.

Chang, Y.N., Huang, J.C., Lee, C.C., Shih, I.L. and Tzeng, Y.M. (2002). Use of response surface methodology to optimize culture medium for the production of lovastatin by Monascus rubber. Enzyme and Microbial Technology. 30: 889-894.

da Cruz, S.H., Cilli, E.M. and Ernandes, J.R. (2002). Structural complexity of the nitrogen source and influence on yeast growth and fermentation. Journal of The Institute of Brewing. 108(1): 54-61.

Dyal, S.D., Bouzidi, L. and Narine, S.S. (2005). Maximizing the production of $\gamma$-linolenic acid in Mortierella ramanniana var. ramanniana as a function of $\mathrm{pH}$, temperature and carbon source, nitrogen source, metal ions and oil supplementation. Food Research International. 38: 815-829.

Folch, J., Lees, M. and Sloane-Stanley, G. H. (1957). A simple method for the isolation of total lipids from animal tissues. Journal of Biological Chemistry. 226: 497-506.

Haalland, P.D. (1989). Experimental design in biotechnology. Marcel Dekker, Inc. New York.

Ibrahim, H.M., Yusoff, W.M.W., Hamid, A.A., Illias, R.M., Hassan, O. and Omar, O. (2005). Optimization of medium for the production of $\beta$-cyclodextrin glucanotransferase using Central Composite Design (CCD). Process Biochemistry. 40: 753-758.

Kendrick, A. and Ratledge, C. (1992). Desaturation of polyunsaturated fatty acids in Mucor circinelloides and the involvement of the novel membrane-bound malic enzyme. European Journal of Biochemistry. 209: 667-673.

Khuri, A.I. and Cornell, J.A. (1987). Response surfaces: design and analysis. Marcel Dekker, Inc. New York.

Lee, S.L. and Chen, W.C. (1997). Optimization of medium composition for the production of glucosyltransferase by Aspergillus niger with response surface methodology. Enzyme and Microbial Technology. 21: 436-440.

Maddon, I.S. and Richard, S.H. (1977). Use of response surface methodology for rapid optimization of 
microbiological media. Journal of Applied Bacteriology. 43: 197-204.

Myers, R.H. and Montgomery, D.C. (1995). Response surface methodology: process and product optimization using designed experiments. WileyInterscience.

Rahman, R.A., Illias, R.M., Nawawi, M.G.M., Ismail, A.F., Hassan, O. and Kamaruddin, K. (2004). Optimisation of growth medium for the production of cyclodextrin glucanotransferase from Bacillus stearothermophilus HR1 using response surface methodology. Process Biochemistry. 39: 2053-2060.

Ratledge, C. (1992). Microbial lipids: commercial realities or academic curiosities, p. 1-14. In Kyle, D.J. and Ratledge, C. (ed.), Industrial applications of single cell oils. AOCS Press, Champaign.

Ratledge, C. (1997). Microbial Lipids. In Kleinkauf, H. \& Dohren, H.V. (eds). Products of secondary metabolism. Biotechnology. 7: 135-197.
Siti Aminah, S., Aidil, A.H. and Wan Mohtar, W.Y. (2004). Effect of concentration of ammonium tartrate and glucose on biomass and lipid production of Absidia sp. 2A1. Proceeding of the $7^{\text {th }}$ National Biology Symposium: Awana Golf \& Country Resort, Genting Highland, Pahang, Malaysia.

Stanbury, P.F., Whitaker, A. and Hall, S.J. (1984). Principles of fermentation technology. 2 ed. Oxford. Butterworth-Heinemann.

Wynn, J.P., Hamid, A.A., Li, Y. and Ratledge, C. (2001). Biochemical events leading to the diversion of carbon into storage lipids in oleaginous fungi Mucor circinelloides and Mortierella alpina. Microbiology. 147: 2857-2864. 